\title{
ERRATUM
}

\section{Validation of prognostic models in intensive care unit-treated pediatric traumatic brain injury patients}

TO THE READERSHIP: An error appeared in the article by Mikkonen et al. (Mikkonen ED, Skrifvars MB, Reinikainen $\mathrm{M}$, et al: Validation of prognostic models in intensive care unit-treated pediatric traumatic brain injury patients. J Neurosurg Pediatr [epub ahead of print June 7, 2019; DOI: 10.3171/2019.4.PEDS1983]).

In the Methods section of the abstract, the final sentence incorrectly stated the outcome for a favorable Glasgow Outcome Scale score as 3-5. The correct GOS score is $4-5$. The corrected sentence is shown below.

The primary outcome was 6-month functional outcome (favorable outcome defined as a Glasgow Outcome Scale score of 4-5). 2019.

The article has been corrected online as of July 19,

Era D. Mikkonen, MD

Helsinki University Hospital and University of Helsinki, Finland

INCLUDE WHEN CITING

Published online July 19, 2019; DOI: 10.3171/2019.7.PEDS1983a.

CAANS 2019, except where prohibited by US copyright law 